[1]. The 3D-DXA and DXA measurements were compared using Student's $t$ test. Categorical variables were compared using Chi-squared test. All hypothesis tests with $p$ value lower than $5 \%$ were considered significant.

Results: Forty-six patients and 46 age and sex-matched controls were evaluated. The mean time of disease's duration was 7.37 years, and the most frequent JIA subtype was Oligoarticular ANA positive. More than $21 \%$ of the patients had an active disease. OP was present in 5 patients and 1 control. Despite not finding significant differences in the prevalence of osteoporosis, JIA patients had lower aBMD at total hip by DXA and lower cortical SBMD by 3D-DXA than controls (Table 1).

Table 1. Comparison of DXA and 3D-DXA measurements between JIA and healthy controls

\begin{tabular}{llll}
\hline Variable & JIA patients $(\mathrm{n}=46)$ & $\begin{array}{l}\text { Healthy controls } \\
(\mathrm{n}=46)\end{array}$ & $\begin{array}{l}P \\
\text { value }\end{array}$ \\
\hline DXA & & & \\
Lumbar aBMD $\left(\mathrm{g} / \mathrm{cm}^{2}\right)$, mean $\pm \mathrm{sd}$ & $1.097 \pm 0.02$ & $1.155 \pm 0.02$ & 0.042 \\
Right femoral neck aBMD $\left(\mathrm{g} / \mathrm{cm}^{2}\right)$, mean $\pm \mathrm{sd}$ & $0.930 \pm 0.02$ & $1.014 \pm 0.01$ & 0.041 \\
Right total hip aBMD $\left(\mathrm{g} / \mathrm{cm}^{2}\right)$, mean $\pm \mathrm{sd}$ & $0.932 \pm 0.02$ & $1.001 \pm 0.01$ & $\mathbf{0 . 0 0 8}$ \\
Lumbar T-score, mean $\pm \mathrm{sd}$ & $-0.716 \pm 0.16$ & $-0.212 \pm 0.16$ & 0.037 \\
Right femoral neck T-score, mean $\pm \mathrm{sd}$ & $-0.563 \pm 0.17$ & $0.087 \pm 0.12$ & 0.036 \\
Right total hip T-score, mean $\pm \mathrm{sd}$ & $-0.721 \pm 0.18$ & $-0.12 \pm 0.13$ & 0.008 \\
3D-DXA & & & \\
Trabecular vBMD $\left(\mathrm{mg}^{\prime} / \mathrm{cm}^{3}\right)$, mean $\pm \mathrm{sd}$ & $180.44 \pm 5.54$ & $194.57 \pm 5.11$ & 0.064 \\
Cortical sBMD $\left(\mathrm{mg} / \mathrm{cm}^{2}\right)$, mean $\pm \mathrm{sd}$ & $147.23 \pm 3.41$ & $161.52 \pm 2.89$ & $\mathbf{0 . 0 0 2}$ \\
Osteoporosis $(\mathrm{WHO}$ definition) & & & \\
Yes, $\mathrm{n}(\%)$ & $5(10.87)$ & $1(2.17)$ & 0.091 \\
No, $\mathrm{n}(\%)$ & $41(89.13)$ & $45(97.83)$ & \\
\hline
\end{tabular}

$D X A$ dual-energy $X$-ray absorptiometry, $s d$ standard deviation, $a B M D$ areal bone mineral density, $3 D-D X A$ three-dimensional dual-energy $\mathrm{X}$-ray absorptiometry, $v B M D$ volumetric bone mineral density, $S B M D$ superficial cortical bone mineral density

Conclusion: JIA patients do not have more OP than controls in our cohort but there are differences in BMD in the different locations and greater involvement of the cortical bone in JIA.

REFERENCES:

[1] Brance ML, et al. Trabecular and cortical bone involvement in rheumatoid arthritis by DXA and DXA-based 3D modelling. Osteoporos Int, 2020 Sep 24.

Disclosure of Interests: None declared

DOI: 10.1136/annrheumdis-2021-eular.742

\section{POS1297 $\quad$ HOW HLA B27 PREVALENCE IN THE POPULATION INFLUENCE ON FEATURES OF JUVENILE IDIOPATHIC ARTHRITIS: DATA FROM SAKHA REPUBLIC (YAKUTIA)}

F. Vinokurova ${ }^{1}$, L. Sorokina ${ }^{2}$, V. Argunova ${ }^{3}$, P. Sleptsova ${ }^{3}$, T. Bourtseva ${ }^{4,5}$, V. Chasnyk ${ }^{2}$, M. Kostik ${ }^{2}{ }^{1}$ Yakut Science Center of Complex Medical Problems, Laboratory of Immunological Researches, Yakutsk, Russian Federation; ${ }^{2}$ Saint-Petersburg State Pediatric Medical University, Department of Hospital Pediatrics, St. Petersburg, Russian Federation; ${ }^{3}$ Republic Hospital № 1 - National Center of Medicine, Pediatric Center, Department of CardioRheumatology, Yakutsk, Russian Federation; ${ }^{4}$ North-Eastern Federal University (NEFU), Department of Pediatrics and Pediatric Surgery of Medical Institute NEFU, Yakutsk, Russian Federation; ${ }^{5}$ Yakut Science Center of Complex Medical Problems, Laboratory of Children Health Monitoring and Medical and Environmental Research, Yakutsk, Russian Federation

Background: Sakha Republic (Yakutia) - SR(Y) is a bid arctic region of Russia with high proportion of aboriginals - Yakutians (50\%), intra-national marriages, increased level of inbreeding and high distribution of HLAB27 among aboriginals $-33 \%$, according the epidemiological studies. The main type of arthritis is ankylosing spondylitis in adults and enthesytis-related arthritis (ERA) of juvenile idiopathic arthritis (JIA) in children. The pattern of arthritis distribution in adults and children in $\mathrm{SR}(\mathrm{Y})$ is differ from Caucasians and similar to Native Americans.

Objectives: Our study aimed to evaluate the features of JIA in aboriginals of $\mathrm{SR}(\mathrm{Y})$, associated with high prevalence of HLAB27 antigen.

Methods: In the retrospective study we included 144 Yakutians who were admitted in the rheumatology department of Yakutsk in 2007-2016 years and $753 \mathrm{JIA}$ patients Caucasian origin in Saint-Petersburg in the same years. We evaluated routine clinical and laboratorial features. HLA B27 was evaluated according the clinical judgement of the attending physicians.

Results: ERA is a main JIA category in Yakutians. The main features the male predominance, higher onset age, high inflammatory activity, lower number of active joints, high incidence of hip and sacroiliac joints involvement, lower levels of psoriasis and uveitis. Yakutians have rare the involvement of cervical spine ( $6 \%$ vs $14 \%$, $\mathrm{p}=0.0000001)$, TMJ ( $1 \%$ vs $6 \%, p=0.027)$, elbow ( $8 \%$ vs $16 \%, p=0.012)$, wrist $(18 \%$ vs $28 \%, p=0.017$ ), MCP ( $7 \%$ vs $21 \%, p=0.00005$ ), PIP ( $8 \%$ vs $25 \%, p=0.00005$ ). The treatment rates of methotrexate and biologics were similar between groups, but in Yakutians the biologics were administered earlier, because methotrexate failed and often was ineffective. The cumulative probability to receive biologics was higher in Yakutians compare to Caucasians: HR=3.4 [2.6; 4.4], $\mathrm{p}=0.000001$ (Figure 1). The main biologic in Yakutians was etanercept (49/70; 70\%). Yakutians received corticosteroids and cyclosporine $A$ rarely, due to low incidence of systemic onset JIA and oligoarthritis with uveitis. It was observed, that the HLA B27 as a risk factors had different significance in Yakutians and Caucasians. HLA B27 presence increased the risk of $E R A O R=2.72(1.3 ; 5.6) p=0.01$ in Yakutians and $O R=69.2(29.5 ; 162.3)$ $p=0.00001$ for Caucasians; for biologic administration: $0,86(0,4 ; 1,8), p=0.529$ and $2,45(1,5 ; 4,0), p=0.0003$, respectively.

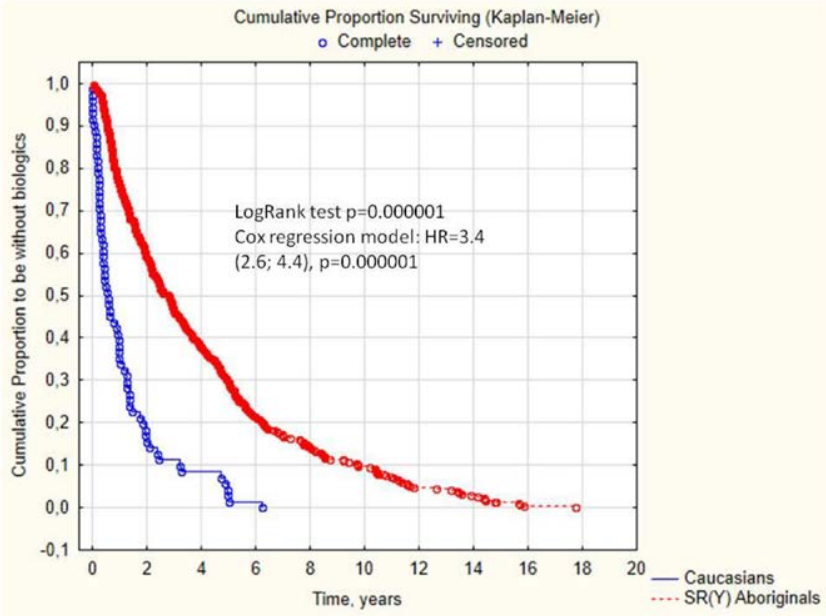

Figure 1. Cumulative probability to leave without biologics between Yakutian and Caucasian JIA patients.

Conclusion: High distribution of HLA B27 antigene in Yakutians, lead to different pattern of JIA categories distributions and patient's management.

This work was supported by the Project of the Ministry of Science and Higher Education of the Russian Federation (basic part of funding to M.K. Ammosov North-Eastern Federal University \#FSRG-2020-0016) and by the RFBR grant \#18-05-600035 Arctika.

Table 1. Differences between Yakutian and Caucasian JIA patients.

\begin{tabular}{|c|c|c|c|}
\hline JIA features & Yakutians, n=144 (\%) & Caucasians, n=723 (\%) & p \\
\hline Gender, boys, n (\%) & $85(59.0)$ & $279(38.6)$ & 0.000006 \\
\hline $\begin{array}{l}\text { Onset age, years } \\
\text { JIA categories, } n(\%)\end{array}$ & $10.6(6.0 ; 13.4)$ & $6.0(3.0 ; 10.3)$ & 0.0000001 \\
\hline Oligoarthritis & $36(25.0)$ & $188(26.0)$ & 0.0000001 \\
\hline Poly, RF (-) & $21(14.6)$ & 248 (34.3) & \\
\hline Poly, RF (+) & $1(0.7)$ & $22(3.0)$ & \\
\hline Systemic onset & $4(2.8)$ & $53(7.3)$ & \\
\hline ERA & $76(52.8)$ & $171(23.7)$ & \\
\hline Psoriatic arthritis & $6(4.2)$ & $41(5.7)$ & \\
\hline Active joints & $4.0(3.0 ; 6.0)$ & $6.0(3.0 ; 12.0)$ & 0.0000001 \\
\hline Uveitis, n (\%) & $16(11.1)$ & $114 / 503(22.7)$ & 0.002 \\
\hline Psoriasis, $\mathrm{n}(\%)$ & $3 / 143(2.1)$ & $46 / 719(6.4)$ & 0.043 \\
\hline Hip involvement & $50(34.7)$ & $146(20.2)$ & 0.0001 \\
\hline Sacroiliitis & 46 (31.9) & $69(9.6)$ & 0.0000001 \\
\hline HLA B27, n (\%) & $76 / 131(58.0)$ & 105/301 (34.8) & 0.00001 \\
\hline ANA, n (\%) & $4 / 46(8.7)$ & 204/444 (46.0) & 0.00001 \\
\hline $\mathrm{RF}, \mathrm{n}(\%)$ & $3 / 141(2.1)$ & $22 / 403(5.5)$ & 0.104 \\
\hline Biologics, primary, n (\%) & 70/144 (48.6) & $347(48.0)$ & 0.892 \\
\hline Time before first biologics, years & $0.6(0.3 ; 1.4)$ & $2.6(1.0 ; 5.4)$ & 0.0000001 \\
\hline
\end{tabular}

Disclosure of Interests: None declared

DOI: 10.1136/annrheumdis-2021-eular.810

\section{POS1298 COMPARISON OF FMF CLINICAL FEATURES} BETWEEN TURKISH AND CRIMEAN TATAR CHILDREN

O. Zhogova ${ }^{1}$, U. Kaya Akca ${ }^{2}$, E. Suspitsin ${ }^{3,4}$, E. Sag ${ }^{2}$, V. Nizhnik ${ }^{3}$, A. Tumakova ${ }^{3}$ S. Ivanoskiy ${ }^{1}$, N. Lagunova ${ }^{1}$, Y. Bilginer ${ }^{2}$, S. Özen ${ }^{2}$, M. Kostik ${ }^{3,5}$. ${ }^{1}$ Crimean Federal University named after V.I. Vernadsky, Pediatry, Simferopol, Russian Federation; ${ }^{2}$ Hacettepe University, Department of Pediatric Rheumatology, Faculty of Medicine, Ankara, Turkey; ${ }^{3}$ Saint Petersburg State Pediatric Medical University, Hospital Pediatry, Saint-Petersburg, Russian Federation; ${ }^{4}$ N.N. Petrov National Research Center of Oncology, Molecular Diagnostics, SaintPetersburg, Russian Federation; ${ }^{5}$ Almazov National Medical Research Centre, 
Autoimmune and Autoinflammatory Diseases, Saint-Petersburg, Russian Federation

Background: Crimean Tatars is an ethnic group in Russia. The presence of familial Mediterranean fever (FMF) has been recognized since 2016.

Objectives: The study aimed to evaluate the prevalence and clinical features as well as genetic aspects of FMF in children of Crimean Tatar (CT) origin and compare them with a cohort from Turkey.

Methods: This retrospective study included all FMF cases in patients of CT origin $(n=18)$ diagnosed in Children's Regional Hospital in Simferopol since 2016. We included 40 consecutive FMF cases between February-March 2020, diagnosed and followed at Hacettepe University, Ankara, Turkey. All children were less than 18 years old at the time of inclusion. The diagnosis of FMF was based on the EULAR criteria (2019). We excluded other autoinflammatory diseases and any doubtful cases. For assessment of MEFV alleles prevalence 127 healthy unrelated CT adults from different parts of Crimea peninsula were included. Sanger sequencing of MEFV exons 2 and 10 was performed in all the patients and controls.

Results: FMF in CT was diagnosed with nearly 5 year-delay, despite the earlier age at onset. CT children had more frequent and prolonged fever, joint involvement (arthritis and arthralgia) and erysipeloid rash compared to Turkish, who had more attacks with chest pain and abdominal pain which last longer. (Table 1) CT had higher white blood cell count, C-reactive protein, erythrocyte sedimentation rate and lower hemoglobin. It might be explained by the fact that the majority of Crimean Tatars were admitted to the clinic during an attack, which was not always the case with Turkish children. Distribution of MEFV pathogenic alleles p.M694V, p.M680I, p.V726A in CT children was $81 \%, 9.5 \%$ and $9.5 \%$, respectively, while in Turks it was $68.6 \%, 14.3 \%$ and $12.9 \%$. Among the CT patients, proportion of homozygotes, compound-heterozygotes and heterozygotes were $11 \%, 6 \%$ and $83 \%$, and among Turkish patients were $45 \% ; 30 \%$; and $25 \%$, respectively. MEFV pathogenic variants were detected in $10.2 \%$ of healthy CT donors: $7.1 \%$ individuals had p.M694V, $1.6 \%$ - p.M680I, 1.6\% - p.V726A. Comorbid diseases including IgA vasculitis, sacroiliitis, JIA, autoimmune hepatitis and inflammatory bowel disease were reported in $5.6 \%$ of CT and $10 \%$ of Turks. The colchicine treatment rate and regimen were similar, but CT received biologics more frequently (44\%) than Turks (22.5\%)

Conclusion: CT is an ethnic group with a significant number of MEFV mutation carriers assuming the expected prevalence of FMF to be as high as 1:385. Thus, any periodic fever in CT patients should be considered as a sign of possible FMF. The clinical course of FMF has some peculiarities in CT patients.

This work supported by the Russian Foundation for Basic Research (grant № 18-515-57001).

Table 1. Comparative data of FMF patients with Turkish and Crimean Tatar origin

\begin{tabular}{llll}
\hline FMF features & Turkish $(\mathbf{n}=\mathbf{4 0})$ & Crimean Tatars $(\mathbf{n = 1 8 )}$ & $\mathbf{p}$ \\
\hline Family history of FMF, $\mathrm{n}(\%)$ & $16(40)$ & $9(50)$ & 0.477 \\
Consanguinity, $\mathrm{n}(\%)$ & $8(20)$ & $6(33)$ & 0.272 \\
Onset age, years & $3.3(2 ; 5)$ & $1.3(0 ; 4)$ & 0.040 \\
Age at FMF diagnosis, years & $4.7(3 ; 8)$ & $9.6(4 ; 14)$ & 0.005 \\
Diagnosis delay, years & $0.9(0 ; 2)$ & $5.5(2 ; 10)$ & 0.00001 \\
Fever, $\mathrm{n}(\%)$ & $33(83)$ & $18(100)$ & 0.058 \\
Episode duration, days & $2.0(2 ; 3)$ & $3.0(3 ; 6)$ & 0.000003 \\
Fever duration, hours & $48.0(48 ; 72)$ & $72.0(72 ; 120)$ & 0.000002 \\
Chest pain, $\mathrm{n}(\%)$ & $12(30)$ & $1(6)$ & 0.039 \\
Chest pain duration, hours & $48.0(24 ; 72)$ & $0.0(0 ; 0)$ & 0.000001 \\
Abdominal pain, $\mathrm{n}(\%)$ & $30(75)$ & $9(50)$ & 0.061 \\
Abdominal pain duration, hours & $48.0(24 ; 48)$ & $24.0(24 ; 24)$ & 0.043 \\
Arthritis, $\mathrm{n}(\%)$ & $10(25)$ & $16(89)$ & 0.000006 \\
Arthralgia, $\mathrm{n}(\%)$ & $19(48)$ & $17(94)$ & 0.0007 \\
Erysipeloid rash, $\mathrm{n}(\%)$ & $0(0)$ & $9(50)$ & 0.000001 \\
\hline
\end{tabular}

Disclosure of Interests: None declared

DOI: 10.1136/annrheumdis-2021-eular.817

\section{\begin{tabular}{|l|l}
\hline POS1299 RISK FACTORS OF TOTAL HIP ARTHROPLASTY IN \\
\hline
\end{tabular} JUVENILE ARTHRITIS WITH HIP INVOLVEMENT}

L. Sorokina ${ }^{1}$, I. Avrusin ${ }^{1}$, R. Raupov ${ }^{1}$, N. Garipova ${ }^{2}$, M. Gharabaghtsyan ${ }^{3}$, S. Khrypov ${ }^{4}$, E. Isupova ${ }^{1}$, E. Gaidar ${ }^{1}$, I. Chikova ${ }^{1}$, M. Dubko ${ }^{1}$, V. Masalova ${ }^{1}$, T. Likhacheva ${ }^{1}$, L. Snegireva ${ }^{1}$, M. Kostik ${ }^{1,5}$. 'Saint-Petersburg State Pediatric Medical University, Department of Hospital Pediatrics, St. Petersburg, Russian Federation; ${ }^{2}$ Almazov National Medical Research Centre, Pediatric Department, St. Petersburg, Russian Federation; ${ }^{3}$ Institute of Child and Adolescent Health (ICAH) with the Arabkir Medical Center, Pediatric Department, Yerevan, Armenia; ${ }^{4}$ Saint-Petersburg Clinical Research-Practical Center for Specialized Healthcare (Oncology), Surgical Department, St. Petersburg, Russian Federation; ${ }^{5}$ Almazov National Medical Research Centre, Autoimmune and Autoinflammatory Diseases, St. Petersburg, Russian Federation

Background: Hip osteoarthritis (HOA) is a severe outcome of juvenile idiopathic arthritis (JIA) itself and also can be result of corticosteroid (CS) treatment, if it was used. Total hip arthroplasty (THA) is the last step in JIA treatment and indicates ineffectiveness of conservative treatment.

Objectives: We aimed to evaluate risk factors which lead to THA in JIA patients with $\mathrm{HOA}$.

Methods: 753 patients aged 2-17 years were included in our retrospective study during the last 10 years. Diagnosis was made according to ILAR criteria. Clinical, laboratory and radial examinations were evaluated. Diagnosis of HOA was made on MRI, CT and planar radiograms and confirmed by morphological examination of removed femoral heads.

Results: Total $153 / 753(20.3 \%)$ patients with JIA had hip involvement. HOA developed in $48 / 153(31.4 \%)$ of JIA patients and $16 / 48$ (33.3\%) of them had THA was undergone. Prevalence of HOA and THA (\%) in JIA subtypes: in polyarticu$\operatorname{lar}(5 / 32(15.6 \%)$ and $8 / 16(50 \%)$, systemic $(6 / 32(18.7 \%)$ and $5 / 16(31.2 \%))$ enthesitis-related (19/32 (59.4\%) and $3 / 16(18.8 \%))$ and psoriatic $(2 / 32(6.7 \%)$ and $0 / 16$ ) subtypes respectively, $p=0,0000001$. Patients who underwent THA initially had higher level of inflammation: elevated ESR (33 vs $5 \mathrm{~mm} / \mathrm{h}, \mathrm{p}=0.002$ ) and CRP (14.7 vs $1.9 \mathrm{mg} / \mathrm{l}, \mathrm{p}=0.03$ ), more active joint, and especially involvement of joints of upper limbs: elbows $(p=0.004)$ and proximal interphalangeal joints $(p=0.001)$, arthritis of subtalar joint $(p=0.02)$. Delayed biologic treatment ( 7.5 vs 3.4 years, $p=0.043$ ) and delayed achievement of remission (9.2 vs 5.6 years, $\mathrm{p}=0.047$ ) were main predictors of THA. Patients with HOA without biologics had increased cumulative probability of THA: HR=1.99 $(1.01 ; 3.98), p=0.049$ (Figure 1). Patients with THA received corticosteroids ( 93.7 vs $50 \%, p=0.003$ ) more often including high dose pulse-therapy regimes, but differences in the cumulative doses were not observed ( 5000 vs $4500 \mathrm{mg}, \mathrm{p}=0.54$ ) between groups, CS administration was independent risk factor of HOA and THA.

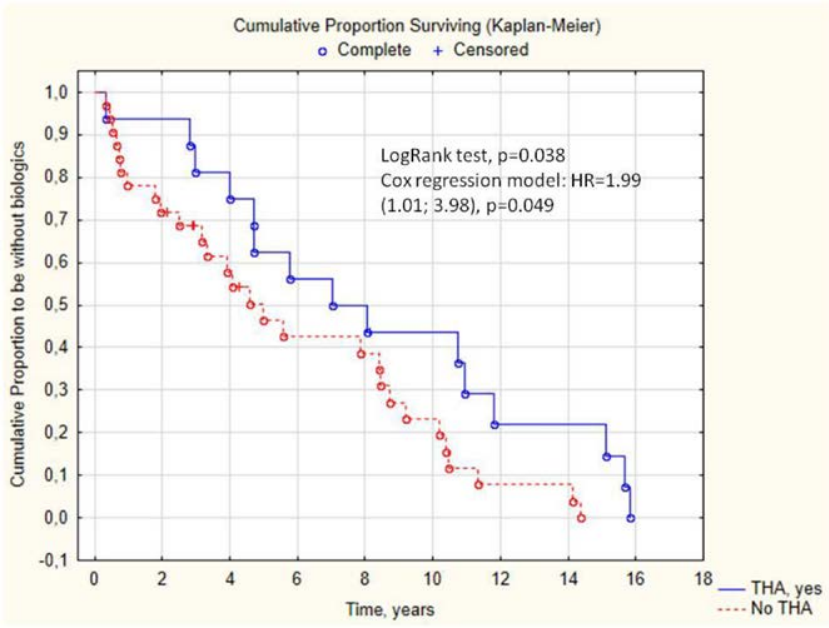

Figure 1. Cumulative probability of THA in JIA patients with hip osteoarthritis.

Conclusion: the main risk factors of THA are systemic and polyarticular course because of their activity, systemic CS and delayed biologic treatment. Corticosteroids should be avoided in those group of patients because of risk of avascular pathway HOA formation.

This work supported by the Russian Foundation for Basic Research (grant № 18-515-57001)

Table 1. The features of JIA patients with hip osteoarthritis depending on

\begin{tabular}{llll}
\hline JIA features & THA, $(\mathrm{n}=16)$ & HOA without THA, $(\mathrm{n}=32)$ & $\mathrm{p}$ \\
\hline Time to THA, years & $5.2(3.6 ; 10.2)$ & $4.6(2.2 ; 8.7)$ & 0.4 \\
Onset age, years & $7.95(3.5 ; 11.1)$ & $8.3(4.3 ; 13.1)$ & 0.5 \\
JIA duration, years & $8.5(6.5 ; 13.2)$ & $5.43(2.8 ; 11.1)$ & 0.07 \\
Polyarticular JIA, $\mathrm{n}(\%)$ & $8(50.0)$ & $5(15.6)$ & 0.037 \\
Systemic JIA, n (\%) & $5(31.3)$ & $6(7.0)$ & 0.037 \\
ANA, $\mathrm{n}(\%)$ & $3 / 8(37.5)$ & $5 / 16(31.3)$ & 0.760 \\
HLA B27, $\mathrm{n}(\%)$ & $3 / 6(50)$ & $9 / 19(47.4)$ & 0.911 \\
RF, $\mathrm{n}(\%)$ & $0 / 9(0)$ & $1 / 15(6.7)$ & 0.429 \\
Uveitis, $\mathrm{n}(\%)$ & $1 / 16(6.3)$ & $3 / 24(12.5)$ & 0.519 \\
ESR, mm/h & $33(13 ; 54)$ & $5(3 ; 27)$ & 0.002 \\
CRP, mg/l & $14.7(2.9 ; 72.3)$ & $1.9(0.3 ; 12.7)$ & 0.03 \\
Active joints, $\mathrm{n}$ & $21.5(8.5 ; 52.5)$ & $9(5 ; 16)$ & 0.02 \\
Elbows, $\mathrm{n}(\%)$ & $11(68.7)$ & $8(25.0)$ & 0.004 \\
Proximal interphalangeal joints, $\mathrm{n}(\%)$ & $10(62.5)$ & $5(15.6)$ & 0.001 \\
Subtalar, $\mathrm{n}(\%)$ & $4(25.0)$ & $1(3.1)$ & 0.02 \\
Pulse-therapy GCS, $\mathrm{n}(\%)$ & $11(68.7)$ & $10(31.3)$ & 0.014 \\
Cumulative GCS dose, mg & $5000(3000 ; 14000)$ & $4500(500 ; 20000)$ & 0.54 \\
Time to biologic, years & $7.6(4.3 ; 11.4)$ & $3.4(1.9 ; 8.6)$ & 0.04 \\
Achievement of remission, years & $9.2(6.6 ; 15.4)$ & $5.6(3.3 ; 11.4)$ & 0.047 \\
\hline
\end{tabular}

